\title{
Jean-Yves Le Guen. \\ Vu des Deux Côtés du Miroir
}

CEL: APPEL de Biscarrosse, 1990.

Dans une note liminaire, Jean-Claude Blondin explique la naissance de ce recueil de poèmes et d'oeuvres pictorales couronné par le Grand Consell Général des Landes, le Grand Prix APPEL et le Prix 1989 du COAC. Jean-Yves Le Guen est connu pour son oeuvre prolifique dans le domaine poétique, romanesque et thêâtral, et aussi en tant que Directeur de revues littéraires et artistiques. Son inspiration provient de son terroir d'origine, la Bretagne, mais dans ce recueil le poète excelle à rendre l'âme pour ainsi dire au paysage landais tel qu'll se présente par plusieurs oeuvres artistiques aux talents divers. Jean-Yves Le Guen ne décrit que rarement loeuvre artistique en vis-à-vis du poème, mais il lui donne plutôt le souffle symbolique et métaphorique qui l'anime. C'est ainsi que nous assistons non à un travail d'illustration mimétique, mais à un dialogue incessant entre deux arts - artistique et poétique - qui gardent l'autonomie et l'originalité de leurs propres voix.

A la fin de chaque poème Jean-Yves Le Guen le dédie à l'artiste (cette autre sensibilité) tout en l'encapsulant d'un petit texte évaluatif qui rend bien compte de la position du poète. Ainsi, certaines oeuvres qui sont assez proches de lui, telle que Anita Claassen et Maurice Buffet, sont "en parfaite osmose avec celle du poète." Le côté surréalisant des oeuvres d'art permet à Jean-Yves Le Guen de composer des textes poétiques avec une force d'impact thématique qui les distingue d'autres inspirations. De ce fait, sa poésie en vers libre avec des rimes et des allitérations qui infusent au texte une musicalité certaine: "L'arbre qui se reconstitue/Mort-né de printemps d'aventure//Nous le soignons à mains si douces/A mots qui chantent des poèmes/Que des oiseaux posent sur lui/Le nid/Lieu-lien de nos rêves."

Toutes les thématiques du poèmes s'articulent autour de ces deux côtés du miroir où dialoguent l'amour et le rêve, la lumière et les ténèbres, le poèmes et la graphie, le temps et l'espace, les mots et le livre, le ciel et l'arc-en-ciel, le vertige et 
122

Bouraoui

l'harmonie, les frémissements de l'âme et les prémisses de l'amour. Nous ne voulons cependant pas donner l'impression qu'il existe des frontières étanches entre ces thematiques, mais comme nous l'avons dit, des dialogues ou des tissages où oeuvre d'art et poème s'harmonisent et se complètent.

Avec ce recueil Jean-Yves Le Guen nous fait vivre des moments privilégiés qui nous font assister à la naissance humaine d'un livre où les qualités de coeur et d'esprit échangent leurs lumières affectives comme le peintre et le poète qui parachèvent cette splendide vision qu'ils ont du monde.

Hedi Bouraoui (Universite York) 